\title{
A.JO'ГE
}

African Journal of Teacher Education

ISSN 1916-7822. A Journal of Spread Corporation

Volume $8 \quad 2019 \quad$ Pages 1-24

\section{The medium of instruction in Ethiopian Higher Education Institutions: Kotebe Metropolitan University Case study}

\author{
Bekalu Atnafu Taye
}

Kotebe Metropolitan University, Ethiopia

\begin{abstract}
The aim of this article is to examine the medium of instruction in Ethiopian higher education institutions and the perceived consequences of the failure to learn a lingua franca. The study was qualitative and it used interviews and focus group discussions (FGDs). Five teachers and five students took part in the interviews and six teachers and six students participated in the FGDs. The findings of the study showed that the role of Amharic as a working language has not been given recognition despite the fact that Amharic was constitutionally granted to be a working language. Due to language barriers, students who are speakers of Oromipha and other languages from the Eastern and Western parts of Ethiopia suffer passivity in the classroom because they do not speak Amharic although Amharic has been taught as a subject in all regional states of the country. Increased identity politics seems to have generated a negative attitude towards Amharic, Ethiopia's former official lingua franca. Non-Amharic native speakers appeared to lose interest in learning Amharic while they were in primary and secondary schools. The absence of an official, common language which could be used for wider communication in higher education has resulted in having challenges among the student population.
\end{abstract}

Key words: medium of instruction, Ethiopia, language, lingua franca, Amharic, Oromipha

\section{Background on multilingualism}

Citing the US Census Bureau, Odugu (2011) indicates that the world's population of approximately 6.9 billion belongs to only 194 or so sovereign states sharing a whopping 6,909 languages. Of the 6,909 languages, an estimated 445 of them are in India, 521 in Nigeria and 36 in Bolivia (Odugu, 2011). In relation to this, Europe and the North America comprise only $7 \%$ of the total number of the world's 
identified languages, whereas Asia and Africa which are the most linguistically and culturally diverse continents account for about $64 \%$ of the world's languages (Jong, 2011). Africa is the most linguistically diversified continent with over 2,086 languages (Chumbow, 2013). This indicates that most nations in Africa are multi-ethnic, multicultural and multilingual as a result of which multilingualism has become a reality in the vast continent.

Since the mid-twentieth century, multilingual societies that had never publicly recognized their multilingualism started to acknowledge their diversity (Garcia, 2007). During the 1960s, ethnic identity became a concern of many groups throughout the world (Fishman, 1989). This greater interest in ethnicity was fueled in part by the independence of many African nations, the increased vitality of indigenous people groups all over Europe, Asia, and the Americas, the growth of civil rights, especially in the United States, and the dynamic movement of immigrants and refugees throughout the world(Garcia,2007). In these changed national, regional and global contexts, indigenous knowledge systems and linguistic and cultural heritage have gained recognition in educational practices of nationstates all across the globe (Singh et al., 2012).

Monolingual education is now openly blamed for the exclusion of language minorities from society; thus, throughout the early 1960s, the use of the mother tongue, along with the majority language, especially in the initial years of schooling, came into practice (Garcia, 2007). European countries that had once insisted on monolingual instruction, such as Great Britain and Spain, adopted bilingual instruction for the education of regional minorities like Welsh and Basque (Siguan, 1988 cited in Garcia, 2001).

Multilingualism, apart from opening doors for quicker and easy communication, has a number of advantages. Nelde (2007) underlined that multilingualism, as well as second and third language acquisition, may be of use to peace and cooperation between nations. For Garcia (2007), bilingualism and multilingualism are important for both language majorities and minorities for cognitive, social, and psychological reasons. In a similar manner, Okal (2014) and Chumbow (2013) suggested that multilingualism practices enhance intellectual flexibility and creativity. Recent studies have indicated that children who grow up in a supportive environment speaking more than one language from an early age are more perceptive and intellectually flexible than those who speak one language. The Ethiopian data also indicate that trilingual education does not detract from overall achievement; on the contrary, it coincides with higher achievement (Heugh, et al., 2007). Hamel (2005) cited in Singh et al. (2012) 
notes that multilingualism is not only a requisite for ecological sustainability, it is also an individual and collective asset; a source of wealth and strength. In addition to cognitive advantages, bilingualism and biliteracy can bring about greater understanding among groups and increased knowledge of each other (Garcia, 2007).

Instruction in a language familiar to pupils immeasurably improves the quality of interaction between teacher and pupil. It also narrows the psychological gulf between home and school, integrates the school better into the local community and gives recognition to the language and culture the child brings to school with positive effects on the self-esteem of individuals and local communities (Ferguson, 2006). Furthermore, it is worthwhile noting that long ago, UNESCO proposed that education is best carried on through the mother tongue of a pupil. The mother tongue plays a huge role in the defining of culture, identity, and in learning new knowledge (Singh et al., 2012). Moreover, from a pedagogical point of view, the use of the child's first language in education has been shown to enhance the academic, linguistic, and cognitive achievement of learners. Ferguson (2013) reviews a substantial body of academic opinions asserting the view that primary education, particularly early primary education and early literacy, is most effectively conducted in a language familiar to the pupil. This is because the potential for the child's cognitive development is strengthened by using the mother tongue during the early years of learning. In a multilingual society, a platform of international declarations and conventions support the learning of at least two languages in education: a mother tongue and a language of the larger community, as well as access to international languages (Ball, 2011).

Vernacularization, the language of the indigenous people has immense benefits for the home countries. First, it is the right of the child to use its mother tongue for schooling. Citing the Ghanaian experience, Owu-Ewie (2006) argued that denying the Ghanaian child the use of his/her native language in education is committing the crime of "linguistic genocide" in education. Next, vernaculariztion, which is an adoption of indigenous language as official language, derives from the modernization and standardization of an indigenous language that redeems those languages which are in the state of extinction due to globalization or internationalization. Despite the fact that many countries developed bilingual and multilingual polices after WW II, most of them still tried adopting the languages of their former colonial rulers (Singh et al., 2012). People supporting internationalism as an ideology, instead of vernacularization, prefer to adopt a non-indigenous language of wider 
communication as an official language, for instance, English in Nigeria, Ghana, India, Sierra Leone etc (Victoria, 2010).

Consequently, many countries have tried to preserve indigenous communities and their linguistic heritages. There is widespread agreement by in the literature that the mother tongue or a local language well known in the community is, in principle, the most suitable medium for education in the initial years of education. The argument is that cognitive development and subject learning is best fostered through teaching in a language the child knows well. Along with globalization and UNESCO declaration, in the past few decades, many programs have been launched by nation states to honor their rich and diverse linguistic heritages of indigenous, minorities and tribal communities, and preserve them for the future generations. Accordingly, Ethiopia has tried since the Dergue regime in the 1980s to entertain linguistic and cultural heritages in the face of the global movement.

\section{Multilingualism in Ethiopia}

The history of nation-building has traditionally involved the promotion of an official language and the repression of others; even liberal states and governments have explicitly or implicitly assumed that the linguistic minorities should accommodate to the majority language (Archibugi: 2005). Nation building projects have gone with the myth that "national cohesion" is possible only through a single common language (Spolsky \& Shohamy, 2000). This view is widespread in both Western and Eastern Europe (Michael, 2007; Jong, 2011) and it was an idea shared by former Ethiopian governments. Consequently, the then national language, Amharic, served as a platform for social solidarity until the coming of EPRDF (Ethiopian People's Revolutionary Democratic Front) government in 1991 and the revised constitution of Ethiopia declared Amharic as the only national official language of the whole empire (Constitution, 1955, Article 125). The primary objective of having one national or official language was to secure national unity for the country. In this regard, Cohen (2006) noted that the assumption of the imperial regime's language policy was to produce national unity; it was necessary to have one language, an assumption that was widely shared at the time. Moreover, it was impossible to try to develop all languages on equal footings due to lack of resources although there was no lack of political willingness on the part of the imperial regime. In the pursuit of having a common language for all its citizens, the linguistic rights of others were threatened and the imperial regimes failed to appreciate the immense potentials of indigenous languages. 
With the overthrow of the imperial government of Haile Selassie and the advent of a Marxist regime, Ethiopia's language policy underwent a radical change. Along with the UNESCO declaration of primary education in mother tongue, the reinforcement of Ethiopian indigenous languages use in school as the medium of instruction became more of a necessity rather than an option. Since the mid twentieth-century, preserving cultural identity through indigenous language education had become an accepted fact. Thus, the Dergue regime gave the necessary recognition to the various indigenous knowledge systems, cultural heritages and the century's old linguistic diversities. For the preservation of distinct cultures, endangered languages and identities, the Dergue established the Institute for the Study of Ethiopian Nationalities (ISEN). The policy was to recognize the linguistic, cultural and social rights of all nationalities. Article 5 of the 1974 National Democratic Revolution programme of Socialist Ethiopia stated that "each nationality has the right to determine its political, economic, and social life, and use its own language" (Victoria, 2010).

After the downfall of the Dergue regime, the Ethiopian People's Revolutionary Democratic Front (EPRDF) established a federal structure in Ethiopia. The country was divided into linguistic zones. The 'EPRDF's constitution' Article 47 (1) classifies the member states of the 'Federal Democratic Republic of Ethiopia"' into nine regional states. According to Article 47, member States of the Federal Democratic Republic are: 1) The State of Tigray, 2) The State of Afar, 3) The State of Amhara, 4) The State of Oromia, 5) The State of Somalia, 6) The State of Benshangul/Gumuz, 7) The State of the Southern Nations, Nationalities and Peoples, 8) The State of the Gambela Peoples and 9) The State of the Harari People. Article 5(3) of the constitution states: "Members of the Federation may by law determine their respective working languages." Of all the indigenous languages, Amharic and Afan Oromo are widely spoken; and for a substantial proportion of Ethiopians, Amharic is used as lingua franca. Furthermore, in the school setting in the State of the Southern Nations, Nationalities and Peoples, in the State of Oromia, Amhara, Benshangul and Gambela, Amharic is said to be given as a subject in primary education.

Because of the importance of mother tongue for the academic success of children, MoE (1994) noted that primary education will be given in nationality languages for the sake of the pedagogical advantage of the child in learning in mother tongue and the rights of nationalities to promote the use of their languages. As a result of this policy position, all members of the federation except the Southern Nations, Nationalities and Peoples (SNNP) adopted their own languages for school instruction. 
Clearly, Ethiopia has too many indigenous languages but none of them has nationwide acceptance. Amharic, which had previously been used by many people and was developed well enough to function as a language of wider communication was not accorded this status during the EPRDF regime. Although the Constitution called Amharic the "working language of the country" (Article 5:2) and it is offered as a subject from grade 3, 4 or 5 and up (MoE, 2002), its status is unclear, and its use in government is ultimately dependent on political will of those in government. Thus, as noted by Cohen (2010), Ethiopia has no single official language; rather, several languages have official roles. Amharic is recognized in the constitution as the working language of the state, but it has not been given the legal status of official national language.

Since the new curriculum became operational according to the 1994 policy, over 20 languages have become mediums of instruction for primary education up to grades 4,6 , or 8 depending on the real conditions in each region (MoE, 2002). That is, local languages in their respective areas are used as mediums of instruction from grades 1 to 6 or 1 to 4 , and thereafter English takes over up to the tertiary level.

Students in various regional states are confined to only their local languages and in spatial terms to a narrower identity. We contend that the post-1991 regime in Ethiopia, despite its promise and claims to provide solutions, has been less successful than expected in managing ethnic tensions in the country, and has basically only 'decentralised' the problems (Abbink 2006; Young 1999; Yohannes et al. 2005). The consequent increase in ethnocentrism would seem to have reduced the rate of assimilation; citizens have never been encouraged to learn the former official language, Amharic, which officially is the country's "working language". Due to the absence of a national unifying language, parents were concerned that the policy of ethnocentrism which encourages the use of only local language might negatively affect their children if they were unable to speak Amharic or English, which might cause them to fail the Grade 8 examinations (Benson et al, 2012). Even the researchers' visits to rural schools in the regional state of Oromia revealed that Amharic is not well understood by many learners and by some not at all (see also Benson et al, 2012). Without a common lingua franca, each regional state has been allowed to use its own language. In the process, the unifying agent, a lingua franca, has been missing. Thus, as these students advance along into higher learning institutions, they do not find a common language among themselves for communication. Students could not learn and use Amharic due to the ethnocentric language policy of the country. To worsen the matter, students' command of 
English has been extremely poor. The standard of competence in English is low among both teachers and students (Bekalu, 2011; Yonas, 2008). Most graduates lack basic English communication skills and the quality of English use among the student population is poor.

In the Ethiopian context, few studies have been done in the area of language policy. Cohen (2010) questioned the level of equity shown in the process of introducing different languages. Daniel and Abebayehu (2006) discussed language planning and changing whereas Sophie (2014) analyzed language policy and social identity in the light of socio-political changes in Ethiopia. None of these studies did empirical analysis of the language of instruction in Ethiopia. So far, no study has been carried out to assess the challenges that university students face with regard to the non-use of a language of wider communication. Studies have shown that non-Amharic speaking students have hardly used Amharic as a communication language up until obtaining admission to higher learning institutions despite the fact that Amharic is given as a subject in primary schools in some linguistic zones in the country. This study therefore tries to fill this gap by reviewing the medium of instruction in Ethiopian higher education sector and the perceived consequences of students failing to learn a lingua franca. The study poses the following research questions:

- What are the media of instruction in the Ethiopian education system?

- What are the perceived consequences of not using a lingua franca in the Ethiopian higher learning institutions?

\section{Methodology}

The target population for this study were students and teachers at Kotebe Metropolitan University, the workplace of the current researcher. To obtain the necessary data for the study, the researcher formed intense and close collaboration with the participants of the study. It is noted by Dornyei (2007) that in qualitative research, the main goal of sampling is to find individuals who could provide rich and varied insights into the phenomenon under investigation so as to maximize what we could learn. This goal was best achieved by means of purposive and snowball sampling techniques. Key respondents who were willing and co-operative were chosen. These chosen participants were asked to recruit further participants who would also be able to shed light on the issue being studied.

In view of this, two focus groups, each having six students and six teachers, participated in focus group discussions; and ten informants, five teachers and five students, took part in the interviews. The 
FGDs and interviews were audio recorded and transcribed using digital audio-recorder. Before the discussion, members were informed that they were being recorded. Participants were also informed about the purpose of the recording.

The qualitative data was transcribed and the verbatim accounts were thematically analyzed. In order to uncover the hidden/deeper meaning of the data, Dornyei's (2007) classification of data analysis was employed. These analytical processes were the following: transcribing the data, coding, categorizing, producing derived data (tentative interpretation) and interpreting the data. The researcher being influenced by Creswell's (2007) argument, eye-catching short quotations were used throughout the analysis.

Ethical research protocol was followed and all the participants willingly took part in the study. They were told that the researcher would mask their names from the analysis and from the data by assigning pseudonyms. In triangulation, corroborating evidence from different sources (from teachers and students) was used. In order to maintain the reliability of the data, the researcher used inter-coder agreements. A friend of the researcher and the researcher coded the transcribed data. In doing so, a high percentage of agreement upon codes was achieved.

\section{Results and Discussion}

\section{The medium of instruction in the Ethiopian education system}

The findings obtained from the qualitative tools were classified according to the objectives of the study and they are presented below. A large proportion of students' responses have had similar themes. The following representative excerpts exemplify the issue.

Alem in the interview session noted:

We learnt every subject in our mother tongue; Amharic and English were taught starting from grade five but we learnt those subjects with our local language, 'Oromiffa' (student, Int. 1.)

Aberash, a student, forwarded the following:

Although Amharic language is introduced at grade five and English language at grade 1, we learnt all subjects in our local language Oromiffa (student, Int.2).

Abayneh in one of the FGD forwarded the following insights: 
The medium of instruction is our first language and students give little value to Amharic and English. Even in Amharic and English classes, the medium of instruction is our mother tongue, $\operatorname{Oromiffa}(F G D, 1)$.

An instructor, Gebru, confirmed the response of the students:

The medium of instruction is the first language of the students which is in line with the declaration of UNESCO but students, coming from the country side use the mother tongue even as a medium of instruction when they were taught other languages (Teacher Int. 1).

Tariku has the following to say:

Before they joined the universities, students learnt only using vernacular language in their primary and secondary schools (Teacher Int. 2).

Chichu, an instructor, in the FGD forwarded the following insights:

After I taught students at Kotebe Metropolitan University for a semester, the students were requested to make performance evaluation. The evaluation form was prepared in Amharic. Most students coming from the countryside left the classroom without filling [them in] claiming that they could not read Amharic (Teacher Int. 3).

The findings of this study show that the medium of instruction in primary and secondary schools are the students' mother tongue. This fits with the UNESCO declaration that proposed that education is best carried on through the mother tongue of a pupil and that the mother tongue plays a major role in the defining of culture, identity, and learning new knowledge (Singh et al., 2012). UNESCO declaration along with Ethiopia's federal structure thus led to the strengthening of local indigenous languages. From the pedagogical perspective, learning is considered to be speeded up when students are able to associate the learning content with their home culture. Moreover, students would not face a language gap between schools and homes when the home language(s) of children is/are the medium of learning in schools.

Although the medium of instruction in the primary schools is the mother tongue of the students, Amharic has been taught as a subject in all regional states of Ethiopia. Despite this, students could not use the language for communication purpose due to the fact that they learn both 'Amharic and English' subjects through their mother tongues. This means that issues in the classroom are presented in the target language but all discussions are made in the native language of the students. The responses of Alem, Aberash and Abayneh verify this assertion. Asking for the reasons that students fail to learn 
Amharic as lingua franca if Amharic has been taught as a subject starting from grade five, the following responses were obtained.

Gemechu forwarded the following:

I do not know the medium of instruction they had but now we hardly communicate with students coming from remote area using indigenous language because students develop antagonistic view[s] towards the language, Amharic. Due to the propaganda heard, we were made not to be united (Teacher Int. 4).

\section{Ali's response:}

Students might learn using any one of the vernacular languages in their respective areas but when these students came to Addis or when they have contact with their fellow Ethiopians coming from other areas, they cannot communicate. We cannot stand as a Nation. We are divided along linguistic lines. As Ethiopians, we are more divided than united (Teacher Int. 5).

Eba has the following to say:

Since the introduction of ethnic federalism in Ethiopia, Amharic language has been regarded as a language of the former colonizer (FGD, teacher)

Haimanot added the points below:

While Amharic teacher came to class, we left the class. We developed prejudice to Amharic language (FGD, student).

Birkie has the following to add,

We did not attend Amharic classes because of the political orientation and the feeling of aversion (student Int.4).

Tafesse has the following to say:

Where Amharic has been discarded as a language of former rulers, great disparities among ethnic groups are noticeably visible which downgrade the unity of the Ethiopian nation (student Int.5).

The following segment of the discussion with Senait also produced a similar point of view:

Researcher: Why do the students fail to use Amharic or English if they learn these subjects starting from grade five? 
Senait: Students do not use English Language because of the poor quality of education and they do not develop Amharic either due to the negative attitude or the impression to Amharic language they have.

Researcher: Why negative attitude?

Senait: Amharic is being considered as the language of the former rulers and this language is highly politicized. Political leaders exacerbate the previous minor clashes or they create fictitious stories for their political advantages. Students coming from regional states were coached with this sentiment (student Int.3).

Students coming from remote areas of Ethiopia, particularly, from 'Oromia' and 'SNNP' regional states have faced a communication challenge and are hardly able to communicate with other students with a lingua franca (common language). The continuing decline in the use of Amharic as a lingua franca and the inadequate usage of English language create a gap in communication. The poor quality of education meant that students cannot understand English language when it is used as a medium of instruction in the classroom and even teachers hardly use English as medium of communication.

Acknowledging the general weakness in English language skills amongst teachers, the Government of Ethiopia established and strengthened 'English Language Improvement Centers' in all universities that provide teacher education so that new teachers can develop the skills to teach English more effectively (MoE, 2015). To make the lesson understood by the students, teachers could switch to Amharic language, assuming that Amharic is the working language of the country but students coming from the 'Oromia Regional States' are unable to follow the lesson due to language barrier. Therefore, students who speak neither Amharic nor English get embarrassed when they enter colleges and universities.

During the Imperial and the Dergue regimes, Amharic was the language of instruction throughout the elementary school level while English was taught as a foreign language from grade three in the elementary schools and became the medium of instruction in grade seven of the junior secondary school (Ayalew, 1964). This continued until the coming of EPRDF. In the foregoing two regimes, out of the school compound, Amharic was used as lingua-franca or language of wider communication across the country. In those days, Amharic served as an ideologically neutral unifying force for the multilingual societies of Ethiopia. But, the language hegemony of Amharic was not 
welcomed by the EPRDF government because the prevalence of Amharic language as a medium of instruction in the education system was assumed to exemplify the exercise of power as well as economic and political domination. In criticizing the previous regimes, the current government (in the Education and Training Policy and Its Implementation document) stated that Amharic was deliberately imposed throughout the country as the official medium of instruction in all primary schools as a tool to deepen and broaden the pattern of ethnic domination (MoE, 2002). Owing to this assertion, EPRDF passionately preached that Amharic was the language of the former rulers. This is witnessed in the responses of research participant Eba and Tafesse who claimed that the language Amharic was considered as the language of former rulers.

This finding corroborates the findings of Záhoř́k \& Wondwosen(2009) who noted that the language issue became a central point of political debates and Amharic was presented as an imperial language. In a linguistic federalism in which diversity is exploited in serving and preserving differences, the Amharic language, which had been a means of a wider communication before the coming into power of EPRDF, has lost its ground. Unfortunately, an absence of common language introduces challenges especially among the student population. Students face serious communication barriers in their interactions within each other and with the entire community at large since there is a lack of a common language in use for wider communication.

Sophie (2014) indicates that there is a huge political drive behind Ethiopians' language policy as well as an increased sense of ethnic and cultural identity. Despite its systematic recognition by the ruling body, the role of Amharic as a working language in the process of nation building was not clearly seen; it was hampered by politically motivated intent. Due to this, non-Amhara students develop a negative impression towards the former lingua franca robbing them of any interest to learn that language while still in the elementary \& secondary schools.

But it is unfortunate to see members of many ethnic groups regret their inability to communicate in Amharic when they go to large cities like Addis Ababa. People have been observed lamenting their failure to speak the language that serves as a bridge among the population of well over hundred million. The measures taken by the current government on language issues are often more informed by political and ideological considerations than strictly educational ones (Ferguson, 2013; Daniel \& Abebayehu, 2006). The government has tried to change every historical incidence including language use to satisfy its immediate political interests. The people of Amhara in the real sense did not benefit from any 
disproportionate socioeconomic and political advantage through the use of Amhara as a working language. As noted by Gebru, the peasants rebelled against the state not particularly because it was controlled and dominated by the Shoan Amhara, but primarily because it was oppressive (Gebru, 1977).

The prejudice against the Amharic language is under scored by participants in this study. Their responses indicate that the language policy is richly politicized and EPRDF's propaganda is responsible for the continuous marginalization of Amharic. The responses of Haile, Birkie, Gemechu and Senait are a good testament to this claim. The rule of EPRDF has produced poor inter-ethnic communication and as a result of this and other concomitant problems, the unity of the country has become more endangered than ever. For the last two decades, it is evident that tribalism and ethnic division have been wide spread in Ethiopia's higher education institutions.

Daniel and Abebayehu (2006) added that the current instructional language policy in Ethiopia is dictated by the ruling party in line with its political ideology rather than being in favour of the students' learning. The current political orientation and increase ethnocentricity reduce the possibility of integration among the various ethnic/linguistic groups. Hence, lingo-centric individuals will be reluctant to learn the language of "their linguistic rivals". Cohen seems to be right to have stated that Ethiopian languages are inherently in competition with one another and an alternative ideological stance would have been preferable to see the use of several languages as complementary rather than antagonistic (Cohen, 2010).

Any linguistic attempt that unifies the country has not been encouraged. A case in point is the Ethiopic script. The Dergue regime decided to use Ethiopic script for transcribing Afaan Oromo, Sidama, Wolayta and other languages because most of them were previously unwritten and the use of one script meant a united system of writing (Záhořík \& Wondwosen, 2009). In contrast to this, the current regime have made Afaan Oromoo, the language of the Oromo people, to be rendered in the Latin alphabet when the Ethiopic script has been proved to be suitable in the Ethiopian context for thousands of years. The official prejudice against the Ethiopic alphabet is believed to be due to the fact that it was the script of the Amhara ethnic group whose influence had been felt in the country for a long period of time in history (Záhořík \& Wondwosen, 2009). In view of the ethno-centric ideology of the government along with its indoctrination, students in higher education institutions largely form friendship based on their ethnic affiliation and contact across various linguistic groups have been minimal. Ethiopian higher learning institutions in recent times have reported a number of ethnic-based 
conflicts among students which are the results of ethnocentric mentality and poor inter group relationships (EHRC, 38 ${ }^{\text {th }}$ special issue, 159; Voice of America: 20 December, 2017).

Adegbija (1994) cited in Matsinhe (2013) noted that language attitudes are one of the main challenges facing the development, promotion and use of African languages, particularly in education. Where the community has a broadly negative view of the target language and its speakers, or a negative view of its relation to them, learning is typically much more difficult. On the other hand, if the community has a positive view of that language, the learning process will be much easier (Bialystock, 2001 cited in Azmi, 2013). As seen in the earlier excerpts from research participants, absence of a common mode of communication creates hindrance for exchanging ideas in the classroom or campus. In a multilingual country like Ethiopia, the nonexistence of language policy or lack of official/national language would produce such gap.

Although education in mother tongue has been the order of the day and was also proposed by international organizations, including UNESCO; UNESCO has at the same time also recommended the use of national and official languages of wider communication, along with some global languages, so that indigenous and marginal communities can be able to participate and contribute to large part of the society (UNESCO, 2003; Singh et al., 2012). Along with this international declaration, a number of multilingual countries have chosen one, two or three languages as languages of wider communication. For example, apart from giving constitutional recognition to the indigenous languages, Article 6 of the Compulsory Education Law of China further specifies that schools should endorse the use of Mandarin as the common language in China; in a similar vein, India adopted a policy called the "Three Language Formula" (TLF) in 1968, according to which Hindi is the national language, English is the language for official businesses along with Hindi and the third language a state-wise recognized language(Singh et al., 2012).

\section{The perceived consequences of the failure to learn a lingua franca in the Ethiopian Higher Learning Institutions}

From the responses that the subjects of the study gave, a number of consequences were mentioned for the failure to have a language of wider communication. Ali, an instructor, in the interview session noted: 
The students' command of English is extremely poor. Then, when you switch to Amharic, students coming from Oromia and the Southern part of Ethiopia would be out of the lesson (Interview, teacher).

Derartu has the following to say:

In most classes, we simply become idle and we ask our friends for help outside the classroom (FGD, student).

Tafesse forwarded the points below:

We cannot follow the lesson since we have been unable to use the language of the wider communication (Student Int.5).

Sara added:

Since students missed the tool of communication, they are not comfortable in the classroom and they have had poor performance (FGD, teacher)

Chichu has the following to say:

I could testify that most students coming from 'Oromia' Regional State fail to use 'Amharic' for communication purpose. They were passive in the classroom because of communication problem (Teacher Int.3).

Bultie has forwarded the following:

The problem, for example, becomes very serious when we are assigned in different groups to do activities. Since our English is poor, we can't communicate effectively; by the same token, we can't speak Amharic and cannot communicate with each other (FGD, student).

Alem stated:

It is good to use our own language to communicate. However, since I can't speak the Amharic or other languages, I face problem to communicate with my classmates (Student Int.1).

Chala noted:

During teaching, teachers use English language. If they think we didn't understand the concept, they translate the ideas in Amharic. The question is how many of us understand Amharic? I can't say that teachers do not know this, but they are compelled to do, no choice (FGD, student). 
Due to communication barrier, students became passive and the level of classroom participation among the student population was low. In the absence of a means of communication, students could not share information and the process of learning could not be enhanced. This could be witnessed from the responses of Aklilu, Derartu, Bultie and Chala. Sharing the Nepal experience, Singhet etal. (2012) noted that a huge number of children drop out of school in Nepal due to various factors, the language of instruction being the major one.

Active participation and high achievement are best fostered in a learning environment where students share a common language. Better scholastic achievement, divergent thinking and cognitive flexibility would be possible when learners have developed multiple language proficiency. In this regard, Odugu (2011) stated that multiple language competence disposes the individual to more advanced cognitive functioning measured by academic achievements.

In today's global society, the ability to speak more than one language is a valuable asset for job opportunity. In this regard, Haile in the interview session stated:

A brother of my wife graduated from one of the Ethiopian universities and he came to Addis in search of a job. He did not get a job due to communication problem. He stayed with us for some time and after] he developed a means of communication and later he secured a job (FGD, teacher).

As can be seen from the excerpts above, career opportunities are tightly linked to using various languages. Being sympathetic to Ethiopian students, Sophie (2014) stated that the students may suffer for the sake of political strategies, as they undoubtedly need a thorough knowledge of Amharic for any kind of formal employment. Knowledge of a common language is indispensable since it is used in administration and in most of the labor market. That is, mastery of many languages is an economic asset and provides access to important socio-economic positions. A survey by the American Council on Education (ACE) realized that it is important to speak another language so as to compete successfully in the global economy (Okal, 2014). Okal (2014) further noted that besides academic and professional credentials, employers also look for fluency in the desired languages as an added advantage. Therefore, being a multilingual is a plus to any job seeker in this millennium. 
Moreover, absence of a language of wider communication would let students be confined to their respective ethnic groups; they would not have an extended form of societal interaction with other students coming from other parts of the country. In this regard, Tesfaye has the following to say,

Even outside the classroom, you could see students forming ethnic-based relationships. All these happened because language is politicized (FGD, Teacher).

Tariku forwarded the following:

Students would find their ethnic members since they have a limited way of forming friendships (Teacher Int.2).

As per the responses of the participants, the absence of a language of wider communication has produced constraints on the harmonious relationships that students could establish. As it can be seen from the response of Tesfaye and Tariku, students at Kotebe Metropolitan University have a tendency to form ethnic-based relationships and there is less contact among members of various ethnic groups. This supports Sophie's (2014) observation that people really do identify more with their own group after the introduction of the policy, but at the same time they refuse to identify with the Amharicspeaking core ("Habesha"). Before the coming of EPRDF, Ethiopians did not see themselves in terms local ethnic terms. The historical associations of the speakers of the various ethnic groups, the broadbased unity, traditional organic relationships and ancestral linkages that promoted national integration have been eroded in Ethiopia since the role of the language as an ethnic flag has been well disseminated since in the rule of the EPRDF government. Taking the challenges mentioned above into consideration, Ethiopians need to have national language/s that promote/s tolerance and intercultural awareness.

\section{The importance of having a lingua franca in Ethiopian higher education institutions}

As discussed above, the use of the child's mother tongue is advantageous to the child's learning in the early stage of schooling, but excessive use of local languages could promote ethnic chauvinism at the expense of national integration as it is being observed in Ethiopia. Participants of the study underscored that there is a need to have a language of wider communication so that citizens could communicate with their fellow Ethiopians by exchanging their feeling, concerns, and thoughts. In this regard, a research participant, Bultie noted:

In addition to using one's nationality language, it is also equally important to be familiar with a common language so as to communicate with others (FGD, Teacher). 
Birkie added:

It is good to have a common language. For example, in our dormitory, the absence of a common language has prevented us from communicating with each other. It is good if everybody speaks all the languages spoken in the country. If not, one common language spoken by every citizen is essential. When we study together, we can exchange abundant ideas among themselves (Student Int. 4)

Mule noted:

In the absence of lingua franca, I use a translator. For example; look now for the moment! I used translator, but I didn't know how far my ideas are expressed (FGD, Student).

Gebru, shared the above sentiments and offered the following:

Absence of a common medium of instruction in our schools put us in different compartments (Teacher Int. 1).

Almaz added the following point:

To live together as a society, we need to share a lot of things of which language is the most important one. We need to have language/s that we all talk (FGD, teacher).

The responses of the subjects advertise the need to learn a lingua franca in the education system of the multilingual nation. Multilingualism practice in education should embrace the indigenous, national/official and foreign languages as equal partners in the language policy development and in education (Okal, 2014). Encouraging the use of indigenous languages in education besides the national and official languages enhances multilingualism.

In the realm of multilingualism, the key forces driving the decisions on language choice have been the goal to maintain the rich linguistic diversity (local), the desire to vouch for national integration (national), and the significance of positioning the nation in the international arena (Kioko,2013).In a similar manner, Fishman (1971) cited in Batibo (2013) calls for the three national aspirations, namely identity, unity and modernity. That is, local language is used for identity whereas national language is for unity and foreign language for modernity. Without national or official languages, multilingualism is seen as a barrier to communication and it weakens national integration and increases the danger of separatist sentiments. Mass mobilization and maximal participation of the people in national affairs can be realized when there is/are national language/s which is/are a key for unity. So it would be better 
to balance the use of local languages and languages of wider communication as medium of instruction in primary education, dividing subjects between the languages in an appropriate manner (Cohen, 2010).

Instead of being confined to ethnic boundaries and being monolingual, most or all Ethiopians could be proficient in two or more languages if the country adopts two or more national or official languages. Being bilingual or multilingual develops a sense of belongingness to the members of that language by enhancing group cohesiveness and team work. Goodall and Roberts (2003) as cited in Thomas (2007) found that making honest attempts to speak the language of others on one's team resulted in the development of trust between team members, thus improving the team's quality of work. The adoption of official languages in a multilingual society promotes a common set of values based on trust and stability that enhances team creativity and performance.

Prejudice can be reduced and intergroup relations could be improved by encouraging more contact across group boundaries. Kurpaska (2010) noted that a common language is supposed to become one of the pillars of unity of a country, the means of communication between the local languages and a means of controlling the inhabitants. More contact is possible while people share a common language of communication. Otherwise, if people do not share their feelings, thoughts, emotions with their fellow Ethiopians using national languages, citizens are becoming discrete groups of people living side by side, without true awareness of one another. Having a common language of communication and forming more contact among members of various ethnic groups would reduce intergroup antipathy.

National unity and ethnic-cultural identity are not necessarily incompatible educational goals but struggles for ethnic dominance and inequitable redistribution of economic resources can pit members of societies as polar opposites (Odugu, 2011). The struggles for ethnic dominance deter Ethiopians not to have a common linguistic basis which is indispensable for national unity. Moreover, the EPRDF government's ethnic national boundaries create a set of mono-ethnic nations which weaken social cohesion. Having a common language does not mean that students learn a lingua-franca at the cost of the mother tongue. Rather students can develop two or more languages without detracting from the unity of the country which is one of Ethiopia's most valuable historical legacies. But due to national level politicization of language policy, students develop prejudice against the language of others as politicians manipulate languages as tools for their political advantages. It is a sign of short-sightedness 
to create a culture of antagonism that dismantles the unity of the country that would not benefit all regional states.

\section{Conclusion}

The objective of this research is to assess the medium of instruction in Ethiopia and to explore the perceived consequences of the failure to learn a lingua franca at Kotebe Metropolitan University. The findings of the study showed that more than twenty local languages are used as medium of instruction from grades 1- 4 and thereafter English takes over up to the tertiary level. Although Amharic language has been taught as a subject starting from grade four or five, students have failed to use the language for communication purpose due to the prejudice against the language.

The language policy of the government seems to be committed to perpetuating ethnic and linguistic distinctiveness and there are no official languages yet in the country. And implementing the federal system of government on the idea of ling-centric, as shown in Ethiopia, was found to widen the gap among the members of various ethnic/linguistic groups.

For the establishment of more contact, people have to share their feelings, emotions, thoughts and ideas with common languages. To that end, the adoption of one, two or three languages as official or national languages like other countries is not an option but it is a necessity. Choosing one or two languages from a range of indigenous languages as official language is not a difficult task since language choice is based on linguistic dominance. Two or three languages, which are numerically and geographically more dominant than others, could be identified as national languages of the nation so that national cohesion and unity can be achieved. Two or more languages can work in complementary relationship to each other, rather than in competition; for example, Switzerland is known for its four lingua francas. In an increasingly globalized and technologically advanced world, drawing language boundaries seems to be awkward and politicizing ethnic differences appears to be a game of the shrewd. Moreover, students should be bi/multilingual and linguistic richness has to be nurtured so as to get a solid and an all-round human capital.

\section{References}

Abbink, J. (2006). Ethnicity and conflict generation in Ethiopia: Some problems and prospects of ethno-regional federalism. Journal of Contemporary African Studies, 24 (3), 389-414. 
Archibugi, D. (2005). The Language of Democracy: Vernacular or Esperanto? A Comparison between the Multiculturalists and Cosmopolitan Perspectives. Italian National Research Council: Political Studies, 53, 537-555.

Azmi, M. (2013). Multilingualism and Personality Traits among Malay Primary School Students in Vernacular Schools. Journal of Humanities and Social Science, 8(3), Retrieved from: www.Iosrjournals. Org.

Ayalew Gebre Sellassie (1964). Three Years Experience in Education. Ethiopian Observer: 8(1), Addis Ababa.

Ball, J. (2011). Enhancing Learning of Children from Diverse Language Backgrounds: Mother Tongue-Based Bilingual or Multilingual Education in the Early Years.UniversityOf Victor. UNESCO, France.

Batibo,H.(2013). Maximizing people's participation through optimal language policy: Lessons from the SADC (Southern African Development Community).In Hamish McIlwraith(ed.)Multilingual Education in Africa: Lessons from the Juba Language-in Education Conference. London: British Council 2013 Brand and Design/C413. www.britishcouncil.org. pp109-115.

Bekalu Atnafu (2011). Determinants of Anxiety in Foreign Language Classes, their relationships and effects. PhD Dissertation: Addis Ababa University, Addis Ababa.

Benson, C., Heugh, K., Bogale, B. \& Gebre Yohannes, (2012). Multilingual education in Ethiopian primary schools (pp. 32-61) In Skutnabb-Kangas, Tove \& Heugh, Kathleen (Eds.) (2012) Multilingual education and sustainable diversity work From periphery to centre. London: Routledge.

Chumbow, B. (2013). Mother tongue-based multilingual education: Empirical foundations, implementation strategies and recommendations for new nations. In Hamish Mcllwraith (ed.) Multilingual Education in Africa: Lessons from the Juba Language-in Education Conference. London: British Council 2013 Brand and Design/C413. www.britishcouncil.org. pp. 37-55

Cohen, G. (2010). Mother Tongue and Other Tongue in Primary Education: Can Equity be achieved with the use of different languages? Retrieved from: file:///C:/Users/User/Desktop/Education\%20and\%20Language/Language

Cohen, G., (2006). The Development of Regional \& Local Languages in Ethiopia's Federal System' in Ethnic Federalism: In David Turton(ed.) The Ethiopian Experience in Comparative Perspective, Eastern African Studies, James Currey Ltd, Oxford, pp. 165-180.

Creswell, J. W. (2007). Qualitative inquiry \& research design: Choosing among five approaches. London: SAGE Publications. 
Daniel Alemu and Abebayehu Tekleselassie (2006). Instructional language Policy in Ethiopia: Motivated by politics or the Educational Needs of children? Planning and Changing, 37(3 \&4), $151-168$.

Dornyei, Z. (2007). Research methods in applied linguistics: Qualitative, quantitative and mixed methodologies. Oxford: Oxford University Press.

Ethiopian Human Rights Council (EHRC). $38^{\text {th }}$ special issue, EHC: 159. Addis Ababa, Ethiopia.

Ethiopian Constitution (1955). The 1955 revised constitution of Ethiopia. www.chilot_me

EPRDF Constitution (1995). The 1995 Constitution of Ethiopia.

Ferguson, G. (2006). Language Planning and Education. Edinburgh University Press, Gibson Ferguson,

Ferguson,G.(2013). The language of instruction issue: Reality, aspiration and the wider context. In Hamish McIlwraith (ed.) Multilingual Education in Africa: Lessons from the Juba Language-in Education Conference. London: British Council 2013 Brand and Design/C413. www.britishcouncil.org. pp 17-22

Fishman, J.A. (1989). Language and Ethnicity in Minority Sociolinguistic Perspective. Clevedon • Philadelphia Multilingual Matters LTD

Garcia,O.(2007)."Bilingual Education." Coulmas, Florian (ed). The Handbook of Sociolinguistics. Blackwell Publishing, Retrieved in 28 December 2007 <http://www.blackwellreference.com/subscriber/tocnode?

Gebru Tareke(1977). Rural protest in Ethiopia, 1941-1970: A study of three rebellions. PhD dissertation. Syracuse University.

Heugh, K., Benson, C., Bogale, B. \&GebreYohannes, (2007). Implications for multilingual education: Student achievement in different models of education in Ethiopia (pp. 239-262). In SkutnabbKangas, Tove\&Heugh, Kathleen (Eds.) (2012) Multilingual education and sustainable diversity work from periphery to centre. London: Routledge.

International Crisis Group (2009). Ethiopia: Ethnic Federalism and its discontents, Africa Report $\mathrm{N}^{\circ} 153-4$ September.

Jong, E. (2011). Foundations for Multilingualism in Education from Principles to Practice. University of Florida, Gainesville: Caslon Publishing.

Kiok, A. N. (2013). Language policy and practice in Kenya: Challenges and prospects. In Hamish McIlwraith(ed.) Multilingual Education in Africa: Lessons from the Juba Language-in Education Conference. London: British Council 2013 Brand and Design/C413. www.britishcouncil.org. pp117-125.

Kurpaska, M. (2010) Chinese Language(s): A Look through the Prism of the Great Dictionary of Modern Chinese Dialects. In Volker Gast (ed.) Trends in Linguistics Studies and Monographs 
215.Berlin Printing: Hubert \& Co. GmbH \& Co. KG, Göttingen. Retrieved from:www.degruyter.com

Matsinhe, S.F. (2013). African languages as a viable factor in Africa's quest for integration and development. In Hamish McIlwraith (ed.) Multilingual Education in Africa: Lessons from the Juba Language-in Education Conference. London: British Council 2013 Brand and Design/C413. www.britishcouncil.org. Pp21-35

Michael C. (2007). Multilingualism.Coulmas Florian (ed.) The Handbook of Sociolinguistics Blackwell Publishing Reference Online, Retrieved from: <http://www.blackwellreference.com/subscriber/tocnode?

MoE (2002). The Education and Training Policy and Its Implementation. Addis Ababa.

MoE (1994). Federal Democratic Republic Government of Ethiopia: Education and Training Policy. Addis Ababa.

MoE (2015). Education Sector Development Program V. Addis Ababa.

Nelde, P.H. (2007). Language Conflict. In Coulmas, Florian (ed). The Handbook of Sociolinguistics Blackwell Publishing, Online. Retrieved from:<http://www.blackwellreference.com/subscriber/tocnode?

Odugu, D. (2011). Education Language Policy Process in Multilingual Societies: Global Visions and Local Agendas in India, Nigeria and Unesco. Unpublished Dissertations. Retrieved from: http://ecommons.luc.edu/luc_diss/166

Okal, B. O. (2014). Benefits of Multilingualism in Education. Universal Journal of Educational Research, 2(3), 223-229. Retrieved from: http://www.hrpub.org.

Owu-Ewie, C. (2006). The Language Policy of Education in Ghana: A Critical Look at the EnglishOnly Language Policy of Education. Selected Proceedings of the 35th Annual Conference on African Linguistics, In John Mugane(ed.) Somerville, MA: Cascadilla Proceedings Project. Pp 76-85. Ohio University, Athens.

Singh, N. K., Shaoan, Z. And Parwez, B. (2012). Globalization and Language Policies of Multilingual Societies: Some Case Studies of South East Asia. Belo Horizonte, 12(2), 349-380.

Sophie,Küspert-Rakotondrainy(2014).Language Policy and Social Identity in the Light of SocioPolitical Changes in Ethiopia. A Comparative Case Study among the Gumuz and Shinasha.ERJSSH, 1 (1), 41-72

Spolsky B. and Elana, S. (2000) Language Practice, Language Ideology, and Language Policy In Richard D. Lambert Nflc, and Elana Shohamy (eds.) Language Policy and Pedagogy.

Amsterdam. John Benjamins Publishing. pp 1-42

Thomas, C. (2007). Language Policy in Multilingual Organizations. Language Policy in Multilingual Organizations Working Papers in Educational Linguistics, 22(1), 81-104, University of Pennsylvania 
UNESCO (2003). Education in a multilingual world. Paris. The United Nations Educational, Scientific and Cultural Organization. Retrieved from: www.unesco.org/education

Victoria, E.U. (2010). Multilingualism in Nigeria: Implications for Implementing the National Policy on Education. A Project Report Presented in Partial Fulfillment of the Requirements for the Award of the Degree: Masters of Arts (M.A) in Linguistics (Sociolinguistics)University Of Nigeria. Department of Linguistics, Igbo and other Nigerian Languages Nsukka.

Voice of America (2017). Amharic Service News. 20 December, 2017.

Yohannes, Gebre Michael, KassayeHadgu and ZerihunAmbaye 2005.Addressing pastoralist conflict in Ethiopia.Africa Peace Forum, Ethiopian Pastoralist Research and Development Association. Inter Africa Group.

Yonas Adaye (2008). The Role of English in Quality Education: Focus on Primary School English: Teachers' Perceptions of Communicative Approaches. In the 'Proceedings of the National Workshop' Organized by Ethiopian Chapter of OSSREA

Young, J. (1999). Along Ethiopia's western frontier: Gambella and Benishangul in transition. The Journal of Modern African Studies, 37 (2), 321-346.

Záhoř́k, J. and Wondwosen Teshome (2009). Debating Language Policy in Ethiopia. Asian and African Studies, 18(1), 80-102 